\title{
Primary Healthcare System of Pakistan: Challenges to Self-Management of Type 2 Diabetes
}

\author{
Rashid M. Ansari, Hassan Hosseinzadeh, Nicholas Zwar \\ School of Public Health and Community Medicine, Faculty of Medicine, UNSW, Sydney, Australia \\ Email: dr.ansarirm@yahoo.com
}

Received 3 June 2016; accepted 19 July 2016; published 22 July 2016

Copyright $@ 2016$ by authors and Scientific Research Publishing Inc.

This work is licensed under the Creative Commons Attribution International License (CC BY).

http://creativecommons.org/licenses/by/4.0/

(c) (i) Open Access

\section{Abstract}

This review article is aimed at describing the primary healthcare system of Pakistan and its challenges in the face of epidemic of type 2 diabetes, focusing particularly on the middle-aged population of rural area of Pakistan. The main concern in Pakistan is that its middle-aged population is facing the onslaught of obesity and overweight due to lack of physical activity. In addition unhealthy eating habits making it more difficult for this population to control their weight. All these factors are contributing to a high risk of type 2 diabetes for the population of Pakistan. This article provides insight into the primary health care system of Pakistan and highlights its deficiencies by identifying that its primary healthcare system has a poor utilization of health care services, the poor accessibility to health system and poor management of diabetes by the healthcare system, gender disparity and inequity in the health care system. The primary objective of this study is to provide an overview of self-management of diabetes among the middle-aged population of Pakistan and to identify the overall deficiencies in the primary healthcare system, its delivery and access to the system, barriers to self-management of diabetes and quality of life in that region.

\section{Keywords}

Type 2 Diabetes, Self-Management, Epidemiology of Type 2 Diabetes, Primary Health Care System of Pakistan, Challenges to Self-Management

\section{Introduction}

\subsection{Self-Management in Context}

This section gives a brief description of self-management of type 2 diabetes in the region of Pakistan, the con-

How to cite this paper: Ansari, R.M., Hosseinzadeh, H. and Zwar, N. (2016) Primary Healthcare System of Pakistan: Challenges to Self-Management of Type 2 Diabetes. Open Journal of Endocrine and Metabolic Diseases, 6, $173-182$. 
cept of self-management and difficulties and barriers the population is facing in managing the diabetes. The patients in Pakistan with type 2 diabetes require self-management education and understanding of this disease which in itself poses a great challenge. The country is facing the greatest challenges for its primary healthcare system in managing the chronic diseases where diabetes is considered a "self-inflicted" disease and there is stigma attached to this disease in the society. The stigma of being "sick person" also affects the diabetic person all his life as a result of being seen as "different” by his colleagues, friends, teachers and community members in all the stages of life cycle.

It is well understood and agreed that- "self-management is required for control of chronic diseases and for prevention of disease complications; however, patients generally do not adhere to self-management recommendations" [1]-[3]. The adherence to the recommendations and barriers are both problematic for "lifestyle" behaviour such as eating patterns and physical activity rather than medication adherence [4]-[6]. This is evident from the culture, tradition and life style behaviour of the people of Pakistan that both the eating patterns and physical activity are posing a great deal of difficulties to middle-aged population in the self-management of their diabetes.

Marzilli [7] has indicated that eating behaviours of others can influence eating behaviours of diabetic patients, especially if they live together; which is the case in Pakistani society where there is a joint family living system. Ecological perspectives also point to the importance of access to key resources in self-management [8]. Healthy eating patterns and physical activity levels are not likely to occur or persist without convenient sources of healthy foods and attractive safe settings. There is a growing interest on the impact of "built environment” on physical activity in recent years [9] [10]. For example, studies have demonstrated the strong negative and positive effects that access to resources for physical activity [11] [12] and consumption of food purchased away from home [13] have on overweight and obesity.

\subsection{The Epidemiology of Type 2 Diabetes}

It is now well known that "Diabetes Mellitus" is one of the main threats to human health (14). Whiting et al. (16) indicated in the recent estimate of International Diabetes Foundation (IDF) that "worldwide there were 366 million people with diabetes in 2011 and 371 million people with diabetes in 2012, with China (92.3 million), India (63 million) and the United States (24.1 million) leading the way and 4.8 million people died due to diabetes and also 4 out 5 people with diabetes live in low and middle income countries" [14] [15].

The cost impact of diabetes is enormous as it causes more than 471 billion dollars to spend on healthcare globally. The prevalence of diabetes in the world is $8.3 \%$ and in comparison the prevalence rate in Pakistan is 7.89\%, and in Australia the prevalence of diabetes has reached to 9.55\% [15]. The global projection for the diabetes epidemic and per region from 2015-2040 is shown in Figure 1. The increase in the prevalence of type 2 diabetes is the main concern in Pakistan as its middle-aged population is facing the onslaught of obesity and overweight due to lack of physical activity. In addition unhealthy eating habits making it more difficult for this population to control their weight [6].

The prevalence of Type 2 diabetes in Pakistan is in the range of $7.6 \%$ (5.2 million populations) to $11 \%$ [16]-[18] and it is estimated that in 2030 it will increase to around 15\% (14 million populations) and as such Pakistan is ranked $7^{\text {th }}$ on diabetes prevalence list by the World Heath Organization [19] and it is among the top 10 countries in the world for people with diabetes aged 20 - 79 years [19]. Jafar et al. [20] has indicated that on the “age-specific prevalence' of overweight and obesity, more than $40 \%$ of women and 30\% of men aged 40 - 60 years were classified as overweight or obese in the population of Pakistan. The category of overweight and obesity was defined as a BMI of $23 \mathrm{~kg} / \mathrm{m}^{2}$ or greater. This definition, based on the revised criteria for Asian populations [21] was lower than the conventional cutoff value of $25 \mathrm{~kg} / \mathrm{m}^{2}$ for populations of European origin. Obesity was defined as a BMI of $27 \mathrm{~kg} / \mathrm{m}^{2}$ or greater

This low ranking of health care system of Pakistan in the world is a great concern and challenge for the country. A variety of factors can be identified here as the leading causes of low ranking such as poor utilization of primary health care services, including poor socio-economic status, lack of physical accessibility to health system, gender disparity and inequity in healthcare system, low level of education, high unemployment, an ageing population making the problem more complicated [22] [23].

Hakeem and Fawwad [24] have mentioned that the epidemiology of diabetes in Pakistan has a combination of risk factors such as strong gene and environment interplay along with in-utero programming in context of low 


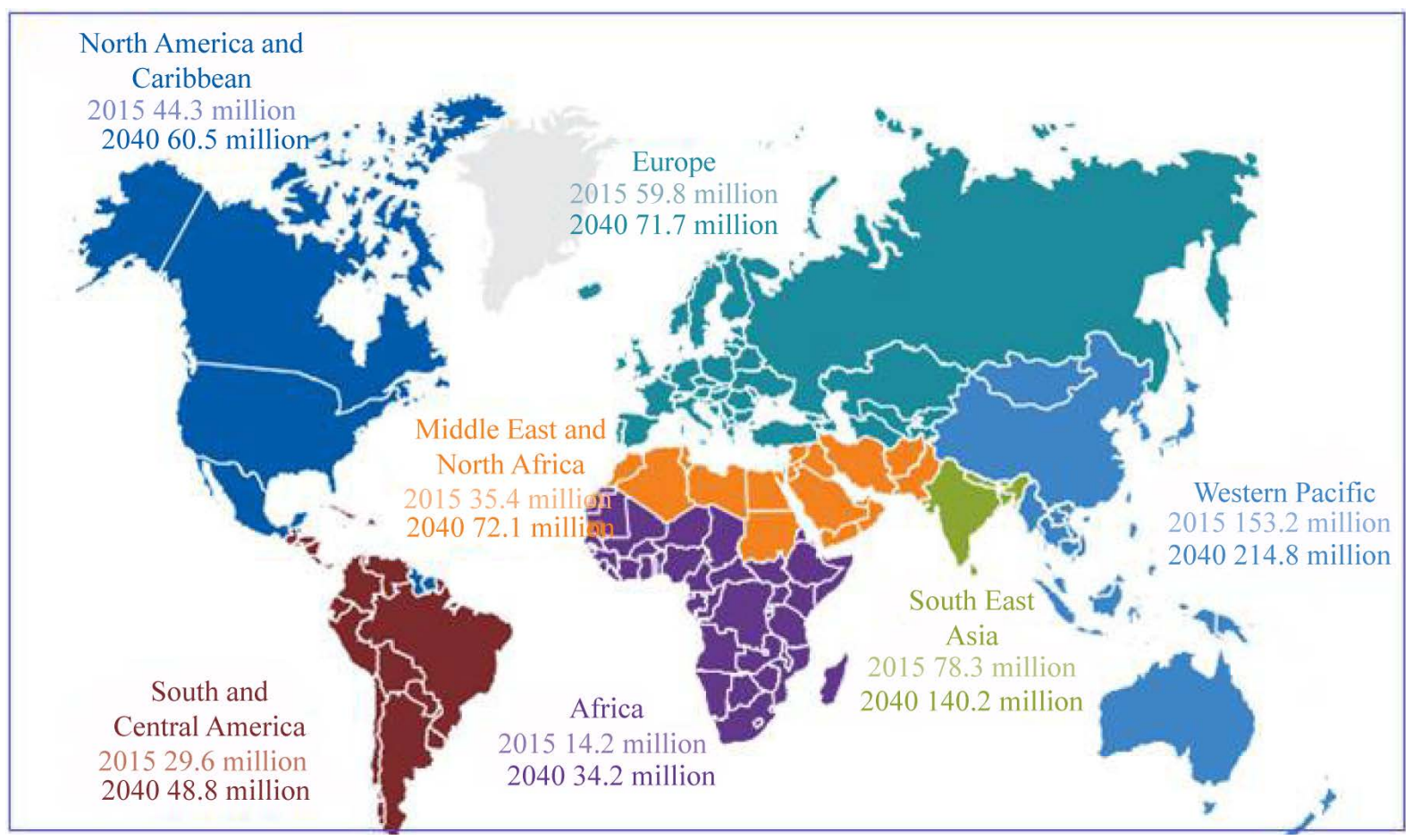

Figure 1. Global projection for diabetes epidemic and per region: 2015-2040 (20 - 79 years). Source [15].

birth weight and gestational diabetes are the main contributors of a high prevalence of type 2 diabetes in Pakis$\tan$. The real burden of diabetes is due to its chronic complications leading to increased morbidity and mortality.

On the basis of the highest age-specific prevalence of diabetes (40 - 60 years) in the country and in line with the latest estimates of International Diabetes Federation on the greatest number of people with diabetes between 40 - 59 years [15], while this review considers diabetic patients in general population, it will specifically focus on the middle-aged population of Pakistan.

\section{Characteristics of Type 2 Diabetes}

Diabetes is a metabolic disease characterized by elevated concentrations of blood glucose for prolonged periods of time, i.e., hyperglycemia [24]. Figure 2 shows the complications of type 2 diabetes which is "a syndrome characterized by insulin deficiency, insulin resistance, and increased hepatic glucose production and these metabolic abnormalities are treated by use of various medications which are designed to correct one or more of metabolic abnormalities [25] [26]”. The complications of type 2 diabetes from micro-vascular and macro-vascular diseases can have a devastating effect on quality of life and impose a heavy burden on healthcare systems.

The treatment for type 2 diabetes differs at various stages of the condition. In its early stages, many people with type 2 diabetes can control their blood glucose levels by losing weight, eating properly and exercising. Many may subsequently need oral medication, and some people with type 2 diabetes may eventually need insulin shots to control their diabetes and avoid the disease's serious complications [26]. Even though there is no cure for diabetes, proper treatment and glucose control enable people with type 2 diabetes to live normal, productive lives. A major advance for people at risk of developing type 2 diabetes-such as family members of those with the condition-occurred recently when it was shown that diet and exercise can prevent or delay type 2 diabetes. People at high risk, who already had early signs of impaired glucose tolerance, significantly reduced their risk by losing only 5 - 7 percent of their body weight and performing moderate physical activity for 30 minutes/day.

Figure 2 shows "Diabetic retinopathy" as one of the complications of type 2 diabetes which is present in $21 \%$ of people in the world at the time type 2 diabetes is diagnosed, more than $60 \%$ have diabetes retinopathy during the first two decades of the disease and diabetic retinopathy is the leading cause of new blindness among adults aged $20-74$ years [26]. Pakistan is ranked $6^{\text {th }}$ among countries with the highest burden of diabetes, 


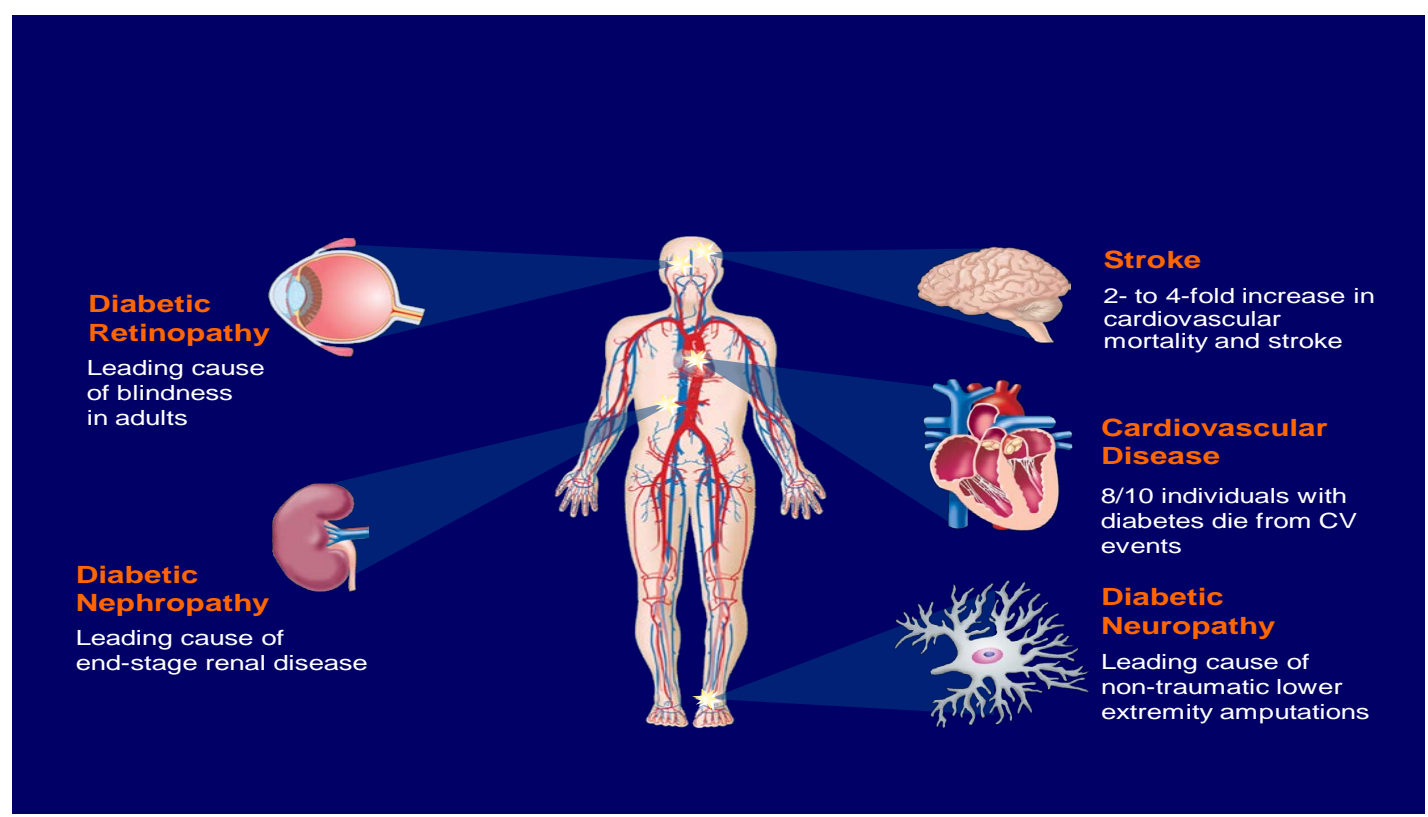

Figure 2. Complications of type 2 diabetes—Source: Saltiel \& Olefsky [26].

however, population-based data on the prevalence of diabetic retinopathy in Pakistan and on the visual impairment due to diabetic retinopathy is lacking and only the hospital-based data is available.

Diabetic nephropathy is present in $18 \%$ of people diagnosed with diabetes and is a leading cause of endstage renal disease. Diabetes is associated with a 2- to 4-fold increase in cardiovascular mortality and stroke. Also, 75\% of individuals with type 2 diabetes die from cardiovascular causes [24].

Diabetic neuropathy is present in $12 \%$ of people at diagnosis and diabetic neuropathy affects approximately $70 \%$ of people with diabetes and is a leading cause of non-traumatic lower extremity amputations. Therefore, early detection and treatment of diabetes is essential in order to reduce the impact of its serious complications [25] [26].

\section{Primary Healthcare System of Pakistan}

\subsection{Background Information}

The Government spending on healthcare of Pakistan is about $\mathbf{0 . 8 \%}$ of GDP which is lower than some neighbouring countries such as Bangladesh (1.2\%) and Sri Lanka (1.4\%) [27]. In Pakistan, only 3.1\% of the total annual budget is allocated for economic, social and community services, and $43 \%$ is spent on debt servicing [28]. In most of the developing countries of South Asia, out-of-pocket household expenditure on health is at times as much as $80 \%$ of medical expenditure [29]. For health expenditure in Pakistan, it is about US\$ 17 per head per year, out of which $\$ 13$ is out-of-pocket private expenditure [30]. The country spends $80 \%$ of its health budget on tertiary care services, which are utilized by only $15 \%$ of the population. In contrast, only $15 \%$ is spent on primary health care services, used by $80 \%$ of the population [31].

\subsection{Pakistan Health Statistics}

The World Health Organization (WHO) ranked Pakistan $122^{\text {nd }}$ in overall health system performance among 191 countries [32]. The health indicators, health funding, and health and sanitation infrastructure are generally poor in Pakistan, particularly in rural areas. About 19 percent of the population is malnourished of which 30 percent of children under age five are malnourished. The leading causes of sickness and death include gastroenteritis, respiratory infections, diabetes, congenital abnormalities, tuberculosis, malaria, and typhoid fever. The United Nations estimated that in 2003 Pakistan's HIV prevalence rate was 0.1 percent among 15 - 49, with an estimated 4,900 deaths from AIDS. Hepatitis B and C are also rampant with approximately 3 million cases of each in the country at the moment. 
The burden of disease due to communicable and non-communicable disease is $52.8 \%$ and $39.4 \%$ respectively with total DALY's 56.1\% and 34.2\% [33]. According to official data, there are 127,859 doctors and 12,804 health facilities in the country to cater for over 170 million people [34]. In 2007 there were 85 physicians for every 100,000 persons in Pakistan that is one doctor for 1225 people.

According to the Ministry of Health Pakistan statistics, there were 13,937 health institutions in the country including 945 hospitals (with a total of 103,285 hospital beds), 4755 dispensaries, 5349 basic health units (mostly in rural areas), 903 mother and child care centers, 562 rural health centers and $290 \mathrm{~TB}$ centers [35] [36]. There is an inequitable distribution of GP's in the country, with $70 \%$ practicing in urban areas where only $30 \%$ of the population lives: in addition, only $10 \%$ to $15 \%$ of GP's in rural areas are females.

\section{Challenges to Primary Healthcare System}

\subsection{Self-Management Approach}

There are no initiatives taken by the government to implement established evidence-based guidelines for selfmanagement of diabetes [37] and practice recommendations' translation to care in Asian countries [38], and as well as in developed countries [39]. Therefore, the need of self-management approaches is much more important for patients with type 2 diabetes and the assessment of quality of diabetes care in the community.

The studies on diabetes knowledge, beliefs and practices among people with diabetes [40] provided further evidence that there was a lack of information available to people with diabetes in Pakistan as the large population has never received any diabetes education at all [40]. This study was carried out in an urban university hospital, where diabetes education may be more readily available as compared to rural areas where people have less access to information and will have even poorer diabetes perception and practices. The other studies carried out in Pakistan on diabetes education and awareness suggested that level of awareness at both physicians and patients along with other community people was very low [41]-[48].

Fisher et al. [49] suggested that the "quality clinical care and self-management are compatible and dependent on each other and without sound care, patient's efforts may be misdirected and expert clinical care will fall far short of its potential, through patient failure to use prescribed medications to control his/her blood sugar or to implement its management plans" [49].

Wagner et al. [50] developed a framework for integrating the resources and support for self-management with key components of clinical care in their chronic care model. A number of studies have also suggested that patient understanding and beliefs about health and illness may be shaped by historical and local contexts [51], whether respondents are thinking about health or behaviour in general or about their own [52], and personal experience and observation [53].

\subsection{Health Services in Local Community}

In Pakistan, the diabetes management programme in the community health clinics are not in a position to help and support the patients of diabetes and the health services in the community are not adequate. There is a great shortage of community doctors and expensive consultations with private doctors pose many problems to patients. The chronic disease care is mostly integrated into the public health system through primary health care. Usually, people with diabetes are referred from primary health-care clinics to specialist diabetes centers.

There are two reasons for this approach. The first reason is that the health care interventions to manage diabetes cases starts with the registration of the patient in a primary health care clinics and the issuing of diabetes card. Medical diagnosis includes a physical examination and laboratory studies. These clinics in Pakistan face special challenges to provide diabetes care to the poor patients as most of these clinics do not meet the evidencebased quality of care standards as compared to the targets established by the American Diabetes Association [54].

\subsection{Structure of Primary Care Services Delivery}

In Pakistan, basic health units are seeing an average of 20 - 25 patients per day where each basic unit has about 10 staff members. The primary care delivery system and satisfaction level have largely remained unchanged during the last three decades. The recent surveys indicate that nationally, not more than $20 \%$ of the people used the first level public sector network for their health care needs [28] [35]. Therefore, the economic constraints, 
lack of good governance and inability to deliver public goods have led to the concept of unleashing the primary care to contracting services in Pakistan [55]-[57].

This primary care contracting was initially implemented in one of the cities in Pakistan and received good results, the situation in the city was improved in terms of utilization of basic health services, community satisfaction, out of pocket expenditure and quality of care. This contracting of primary health care service has been extended to several cities and the provinces and is a major change in public sector health system especially for the people living in rural area of Pakistan.

\subsection{Patterns of Morbidity in Population}

The morbidity is a multidimensional concept, and time trends in the different dimensions can vary [58]. Increases in physiological dysregulation, disease onset, functioning loss, and frailty are all parts of the process of health change that can precede death [58]. The patterns of morbidity in the population of Pakistan include cardiovascular diseases, chronic obstructive pulmonary disease, heart failure, diabetes and depression. CVD is a major cause of morbidity in this population followed by diabetes and its complications.

In the past, the studies carried out in the region of Pakistan highlighted the morbidity patterns presented at the primary health care centers in association with the socio-demographic characteristics [59]. In comparison of American population with that of Pakistani population, it was demonstrated that Pakistani population had higher rate of under nutrition and hypertension. There are urban and rural differences and economic gradients in indicators of under nutrition and risk factors for heart disease and cancers.

The population of Pakistan has two levels of trends in morbidity namely the macro level and micro level which has triggered changes to primary health care in this population. At a macro level, the trends included an increase in ageing population with chronic and complex diseases and require comprehensive care. At a micro level, the trends increased in coordinating care, managing the comorbidity and teams and making the time to build trust and relationship [60]. These patterns of morbidity have an overall impact on general practice in terms of maintaining the important characteristics of primary health care. These changes in primary health care are posing great challenges and require developing primary health care research to address the challenges of care for people with comorbidities.

\section{Barriers to Diabetes Care}

It was identified by Glasgow et al. [61] that two types of barriers (internal and external) exist. The psychosocial and cultural barriers to diabetes care (self-management) and quality of life. While psychosocial barrier is related to interpersonal factors that impede diabetes self-management, the other external barrier is related to biological factor such as organization of medical care and community and cultural influences [62].

The psychosocial barriers influence longer-term outcomes, such as glycemic control (HbA1c) and eventually development of diabetes complications. The middle-aged population of Pakistan have both psychosocial and cultural barriers to their diabetes management and the literature review revealed non-compliance on eating patterns, lack of physical activity, lack of family and cultural support and difficulties in accessing medical care [40]-[48].

There is evidence to support this analysis from the review which was in agreement with Brown and Hedges [63] that psychosocial barriers such as stress, depression and low level of efficacy, lack of social and community support may have direct as well as indirect effects on metabolic outcome. Therefore, lack of social support, particularly from friends and family is also considered a barrier to dietary adherence and self-management [63].

In order to assess the needs and barriers for delivery of quality diabetes education, the most important consideration is the diversity of patient population from multiple perspectives, including education, levels of knowledge, management practices, disease control, and importance of diabetes education. Non-compliance with defined management practices requiring lifestyle behaviour changes which is consistent with the findings of Glasgow et al. [61].

Wang et al. [64] have identified socio-cultural practices leading to dietary non-compliance and lack of motivation for exercise as important factors. This review highlighted the socio-cultural factors hampering change, especially for women, such as non-availability of socially appropriate facilities close to their homes where they can exercise. It is therefore necessary for educators to identify settings and facilitate support groups to promotebehavioural change. 


\section{Recommendations}

In order to improve the current status of healthcare system of Pakistan, it is recommended that decision-makers at all levels need to appraise the variation in health system performance, identify factors that influence it and articulate policies that will achieve better results in a variety of settings. It is recommended by regional health systems observatory, that meaningful, comparable information on health system performance, and on key factors that explain performance variation, can strengthen the scientific foundations of health policy at national, regional and international levels. In addition, community participation should be encouraged in all the aspects and at all levels so as to provide quality care according to community interests and to make all the programs successful.

The health services in the community can be improved by making use of on-going follow-up and support for the self-management of diabetes which has shown promising results [65]. For the poor patients in that region of Pakistan where access to the community doctors is not easy and private doctors are not affordable, support may be provided through telephone calls [66] or the internet [67]. It has been reported that telephone monitoring of patients, combined with nurse follow-up and tailored information has been shown to reach low income patients and helped them managed their blood sugar level and reduced levels of depression [68].

Another strategy to improve the health services in the community is the group visit to medical clinics by the patients of diabetes [69] in which all the patients in a particular category visit the physicians for general checkup including the educational and supportive discussions. Evaluation of this type of strategy has indicated impressive effects on glycosylated hemoglobin and other measures to usual care [70].

\section{Conclusions}

This review has provided information on the self-management approach of the people suffering with diabetes in the middle-aged population of Pakistan and identified the barriers to self-management of diabetes and quality of life in that region. This review will also contribute to providing information on the quality health care for diabetic patients in health clinics in that region and recommended a multifactorial approach emphasizing patient education, culturally-tailored diabetes self-management intervention, improved training in behavioural change for providers, and enhanced delivery system.

This review has demonstrated that Pakistan health care system is inefficient and in order to improve the healthcare system and its effectiveness, it would require rational policies to provide efficient, effective, acceptable, cost effective, affordable and accessible services to its population. The healthcare system performance measurement and management frameworks still need to address some conceptual issues concerning effectiveness and quality on the basis of the criteria suggested by World Health Organization.

In addition, it is important to provide awareness and knowledge to diabetic patients and to help them to manage their diabetes. Therefore, the information about the healthcare system of Pakistan provided in this review and the importance of diabetes education and awareness highlighted here will enhance the knowledge and understanding of patients of diabetes with regards to self-management of diabetes.

\section{Conflict of Interest Statement}

The authors declare that there are no conflicts of interest.

\section{References}

[1] Sherbourne, C.D., Hays, R.D. and Ordway, L. (1992) Antecedents of Adherence to Medical Recommendations: Results from the Medical Outcomes Study. Journal of Behavioral Medicine, 15, 447-468. http://dx.doi.org/10.1007/BF00844941

[2] Gochman, D.S. (1997) Handbook of Health Behaviour Research II. Plenum Press, New York.

[3] Glasgow, R.E. and Eakin, E.G. (1998) Issues in Diabetes Self-Management. In: Shumaker, S.A., Schron, E.B., Ockene, J.K. and McBee, W.L., Eds., The Handbook of Health Behaviour Change, Springer, New York, 435-461.

[4] Brown, S.A. (1990) Studies of Educational Interventions and Outcomes in Diabetic Adults: A Meta-Analysis Revisited. Patient Education and Counselling, 16, 189-215. http://dx.doi.org/10.1016/0738-3991(90)90070-2

[5] Ansari, R.M., Dixon, J.B. and Coles, J. (2015) Type 2 Diabetes: Challenges to Health Care System of Pakistan. International Journal of Diabetes Research, 4, 7-12. 
[6] Ansari, R.M. (2009) Effect of Physical Activity and Obesity on Type 2 Diabetes in Middle-Aged Population. Journal of Environmental and Public Health, 2009, 4-9. http://dx.doi.org/10.1155/2009/195285

[7] Marzilli, G. (1999) The Effects of Social Support on Eating Behavior in Patients with Diabetes.

[8] Glasgow, R.E., Toobert, D.J., Barrera, M.J., et al. (2005) The Chronic Illness Resources Survey: Cross-Validation and Sensitivity to Intervention. Health Education Research, 20, 402-409. http://dx.doi.org/10.1093/her/cyg140

[9] Frank, L.D., Engelke, P.O. and Schmid, T. (2003) Health and Community Design: The Impact of the Built Environment on Physical Activity. Island Press, Washington DC.

[10] Frumkin, H., Frank, L. and Jackson, R. (2004) Urban Sprawl and Public Health: Designing, Planning, and Building for Healthy Communities. Island Press, Washington DC.

[11] Huston, S.L., Evenson, K.R., Bors, P., et al. (2003) Neighbourhood Environment, Access to Places for Activity, and Leisure-Time Physical Activity in a Diverse North Carolina Population. American Journal of Health Promotion, 18, 58-69. http://dx.doi.org/10.4278/0890-1171-18.1.58

[12] Ewing, R., Schmid, T. and Killingsworth, R. (2003) Relationship between Urban Sprawl and Physical Activity, Obesity, and Morbidity. American Journal of Health Promotion, 18, 47-57. http://dx.doi.org/10.4278/0890-1171-18.1.47

[13] Thompson, O.M., Ballew, C., Resnicow, K., et al. (2004) Food Purchased Away from Home as a Predictor of Change in BMI Z-Score among Girls. International Journal of Obesity and Related Disorder, 28, 282-289.

[14] Narayan, K.M.V. (2005) The Diabetes Pandemic: Looking for the Silver Lining. Clinical Diabetes, 23, 51-52. http://dx.doi.org/10.2337/diaclin.23.2.51

[15] International Diabetes Federation (2015) Diabetes Prevalence.

[16] Whiting, D.R., Guariguata, L., Weil, C. and Shaw, J. (2011) IDF Diabetes Atlas: Global Estimates of the Prevalence of Diabetes for 2011 and 2030. Diabetes Research and Clinical Practice, 94, 311-321. http://dx.doi.org/10.1016/j.diabres.2011.10.029

[17] Jafar, T.H., Levey, A.S., White, F.M., et al. (2004) Ethnic Differences and Determinants of Diabetes and Central Obesity among South Asians of Pakistan. Diabetic Medicine, 21, 716-723. http://dx.doi.org/10.1111/j.1464-5491.2004.01140.x

[18] Shera, A.S., Jawad, F. and Maqsood, A. (2007) Prevalence of Diabetes in Pakistan. Diabetes Research and Clinical Practice, 76, 219-222. http://dx.doi.org/10.1016/j.diabres.2006.08.011

[19] Shaw, J.E., Sicree, R.A. and Zimmet, P.Z. (2010) Global Estimates of the Prevalence of Diabetes for 2010 and 2030. Diabetes Research and Clinical Practice, 87, 4-14. http://dx.doi.org/10.1016/j.diabres.2009.10.007

[20] WHO Expert Consultation (2004) Appropriate Body-Mass Index for Asian Populations and Its Implications for Policy and Intervention. Lancet, 363, 157-163. http://dx.doi.org/10.1016/S0140-6736(03)15268-3

[21] Jafar, T.H. and Chaturvedi, N. (2006) Pappas G: Prevalence of Overweight and Obesity and Their Association with Hypertension and Diabetes Mellitus in an Indo-Asian Population. Canadian Medical Association Journal, 175, 10711077. http://dx.doi.org/10.1503/cmaj.060464

[22] National Health Survey of Pakistan (NHSP). Health Profile of the People of Pakistan. Pakistan 1998, Pakistan Medical Research Council, Islamabad. 1990-1994.

[23] Khuwaja, A.K., Khowaja, L.A. and Cosgrove, P. (2010) The Economic Costs of Diabetes in Developing Countries, Some Concerns and Recommendations. Diabetologia, 53, 389-390. http://dx.doi.org/10.1007/s00125-009-1581-7

[24] Hakeem, R. and Fawwad, A. (2010) Diabetes in Pakistan, Epidemiology, Determinants and Prevention. Journal of Diabetology, 3, 4.

[25] Gerich, J.E. (2005) The Importance of Tight Glycemic Control. The American Journal of Medicine, 118, 7-11. http://dx.doi.org/10.1016/j.amjmed.2005.07.051

[26] Saltiel, A.R. and Olefsky, J.M. (2001) Diabetes. American Family Physician, 63, 1747-1756.

[27] World Bank (1999) World Development Report 1998/99, Knowledge for Development. Oxford University Press, New York.

[28] Government of Pakistan (2000) Ministry of Finance. Budget 2001-2002, Finance Division.

[29] World Bank (1998) Raising a Healthier Population. South Asia Brief, Washington DC.

[30] Word Bank (2002) Pakistan Poverty Assessment. Poverty in Pakistan, Vulnerabilities, Social Gaps, and Rural Dynamics, South Asia Region.

[31] Hunte, P. and Sultana, F. (1992) Health Seeking Behavior and the Meaning of Medications in Balochistan, Pakistan. Social Science \& Medicine, 34, 1385-1397. http://dx.doi.org/10.1016/0277-9536(92)90147-I

[32] WHO. (2000) The World Health Report 2000. Health Systems, Improving Performance, Geneva, World Health Or- 
ganization.

[33] Mathers, C.D., Lopez, A.D. and Murray, C.J.L. (2006) The Burden of Disease and Mortality by Condition, Data, Methods and Results for 2001. Oxford University Press, New York.

[34] World Population Prospects (2014) The 2006 Revision Population Database. http://esa.un.org www.census.gov

[35] National Institute of Population Studies (NIPS) (2007) National Institute of Population Studies and Measure DHS. Pakistan Demographic and Health Survey 2006-07, Preliminary Report, Calverton, MD, Macro International Inc.

[36] Shaikh, B.T. and Hatcher, J. (2004) Health Seeking Behaviour and Health Service Utilization in Pakistan, Challenging the Policy Makers. Journal of Public Health, 27, 49-54. http://dx.doi.org/10.1093/pubmed/fdh207

[37] American Diabetes Association (2006) Standards of Medical Care in Diabetes. Diabetes Care, 29, S4-S42.

[38] Rayappa, P.H., Raju, K.N.M., Kapur, A., Bjork, S., Sylvest, C. and Dilip Kumar, K.M. (1998) The Impact of SocioEconomic Factors on Diabetes Care. International Journal of Diabetes in Developing Countries, 19, 7-15.

[39] Chin, M.H., Auerbach, S.B., Cook, S., Harrison, J.F., et al. (2000) Quality of Diabetes Care in Community Health Centers. American Journal of Public Health, 90, 431-434. http://dx.doi.org/10.2105/AJPH.90.3.431

[40] Rafique, G. and Shaikh, F. (2000) Identifying Needs and Barriers to Diabetes Education in Patients with Diabetes. Journal of Pakistan Medical Association, 56, 347-352.

[41] Ali, M., Khalid, G.H. and Pirkani, G.S. (1998) Level of Health Education in Patients with Type 2 Diabetes Mellitus in Quetta. Journal of Pakistan Medical Association, 48, 334-336.

[42] Jabbar, A., Contractor, Z., Ebrahim, M.A. and Mahmood, K. (2001) Standard of Knowledge about Their Disease among Patients with Diabetes in Karachi, Pakistan. Journal of Pakistan Medical Association, 51, 216-218.

[43] Shera, A.S., Jawad, F. and Basit, A. (2002) Diabetes Related Knowledge, Attitude and Practices of Family Physicians in Pakistan. Journal of Pakistan Medical Association, 52, 465-470.

[44] Hasan, Z.U., Zia, S. and Maracy, M. (2000) Baseline Disease Knowledge Assessment in Patients with Type 2 Diabetes in a Rural Area of Northwest of Pakistan. Journal of Pakistan Medical Association, 54, 67-73.

[45] Adil, M.M., Alam, A.Y. and Jaffery, T. (2005) Knowledge of Type 2 Diabetes Patients about Their Illness, Pilot Project. Journal of Pakistan Medical Association, 55, 221-224.

[46] Sabri, A.A., Qayyum, M.A., Saigol, N.U., Zafar, K. and Aslam, F. (2007) Comparing Knowledge of Diabetes Mellitus among Rural and Urban Diabetics. McGill Journal of Medicine, 10, 87-89.

[47] Ulvi, O.S., Chaudhary, R.Y., Ali, T., et al. (2009) Investigating the Awareness Level about Diabetes Mellitus and Associated Factors in Rural Islamabad. Journal of Pakistan Medical Association, 59, 798-780.

[48] Afridi, M.A. and Khan, M.N. (2003) Role of Health Education in the Management of Diabetes Mellitus. Journal of the College of Physicians and Surgeons-Pakistan, 13, 558-561.

[49] Fisher, E.B., Brownson, C.A., O’Tool, M.L., et al. (2005) Ecological Approaches to Self-Management: The Case of Diabetes. American Journal of Public Health, 95, 1523-1535. http://dx.doi.org/10.2105/AJPH.2005.066084

[50] Wagner, E.H., Austin, B.T. and Von Korff, M. (1996) Organizingcare for Patients with Chronic Illness. Milbank Quarterly, 74, 511-544. http://dx.doi.org/10.2307/3350391

[51] Macfarlane, A. and Kelleher, D. (2002) Concepts of Illness Causation and Attitudes to Health Care among Older People in the Republic of Ireland. Social Science \& Medicine, 54, 1389-1400. http://dx.doi.org/10.1016/S0277-9536(01)00121-6

[52] French, D.P., Senior, V., Weinman, J. and Marteau, T.M. (2001) Causal Attributions for Heart Disease: A Systematic Review. Psychology \& Health, 16, 77-98. http://dx.doi.org/10.1080/08870440108405491

[53] Davison, C., Smith, G.D. and Frankel, S. (1991) Lay epidemiology and the prevention paradox. Sociology of Health \& Illness, 13, 1-19. http://dx.doi.org/10.1111/1467-9566.ep11340301

[54] American Diabetes Association (2000) Clinical Practice Recommendations 2000. Diabetes Care, 23, S1-S116.

[55] Nishtar, S. (2006) The Public-Private Interface, More than “a Driver’s Economic Growth”. View Point, Pakistan Health Policy Forum, Heartfile, Islamabad.

[56] Shaikh, B.T. and Hatcher, J. (2004) Health Seeking Behaviour and Health Service Utilization in Pakistan, Challenging the Policy Makers. Journal of Public Health, 27, 49-54. http://dx.doi.org/10.1093/pubmed/fdh207

[57] Shaikh, B.T., Rabbani, F. and Safi, N. (2010) Contracting of Primary Health Care Services in Pakistan, Is up Scaling a Pragmatic Thinking? Journal of Pakistan Medical Association, 60, 387-389.

[58] Crimmins, E.M. (1996) Mixed Trends in Population Health among Older Adults. Journal of Gerontology: Social Sciences, 51, S223-S225. http://dx.doi.org/10.1093/geronb/51B.5.S223 
[59] Anjum, Q., Alam, E., Usman, J., Usman, J., Shaikh, S. and Ahmed, Y. (2006) Morbidity Pattern and Utilization of a Primary Health Care Center in a Low Socioeconomic Area of Karachi. Journal of Pakistan Medical Association, 56, 13-16.

[60] Martin, L., Freedman, V.A., Schoeni, R. and Andreski, P.M. (2010) Trends in Disability and Related Chronic Conditions among People Ages Fifty to Sixty-Four. Health Affairs, 29, 725-731. http://dx.doi.org/10.1377/hlthaff.2008.0746

[61] Glasgow, R.E., Toobert, D.J. and Gillette, C.D. (2001) psychosocial Barriers to Diabetes Self-Management and Quality of Life. Diabetes Spectrum, 14, 33-41. http://dx.doi.org/10.2337/diaspect.14.1.33

[62] Starfield, B. (2003) Primary and Specialty Care Interfaces: The Imperative of Disease Continuity. British Journal of General Practice, 53, 723-729.

[63] Brown, S.A. and Hedges, L.V. (1994) Predicting Metabolic Control in Diabetes: A Pilot Study Using Meta-Analysis to Estimate a Linear Model. Nursing Research, 43, 362-368. http://dx.doi.org/10.1097/00006199-199411000-00008

[64] Wang, C.Y., Abbott, L., Goodbody, A.K., Hui, W.T. and Rausch, C. (1999) Development of a Community-Based Diabetes Management Program for Pacific Islanders. Diabetes Educator, 25, 738-746. http://dx.doi.org/10.1177/014572179902500506

[65] Norris, S.L., Lau, J., Smith, S.J., et al. (2002) Self-Management Education for Adults with Type 2 Diabetes: A Meta-Analysis of the Effect on Glycemic Control. Diabetes Care, 25, 1159-1171. http://dx.doi.org/10.2337/diacare.25.7.1159

[66] Weinberger, M., Kirkman, M.A., Samsa, G.P., et al (1995) A Nurse-Coordinated Intervention for Primary Care Patients with Non-Insulin-Dependent Diabetes Mellitus, Impact on Glycemic Control and Health-Related Quality of Life. Journal of General Internal Medicine, 10, 59-66. http://dx.doi.org/10.1007/BF02600227

[67] Mckay, H.G., Feil, E.G., Glasgow, R.E. and Brown, J.E. (1998) Feasibility and Use of an Internet Support Service for Diabetes Self-Management. Diabetes Educator, 24, 174-179. http://dx.doi.org/10.1177/014572179802400207

[68] Piette, J.D, Weinberger, M., Kraemer, F.B. and McPhee, S.J. (2001) Impact of Automated Calls with Nurse Follow-Up on Diabetes Treatment Outcomes in a Department of Veterans Affairs Health Care System: A Randomized Controlled Trial. Diabetes Care, 24, 202-208. http://dx.doi.org/10.2337/diacare.24.2.202

[69] Beck, A., Scott, J., Williams, P., et al. (1997) A Randomized Trial of Group Outpatient Visits for Chronically Older HMO Members, the Cooperative Health Care Clinic. Journal of the American Geriatrics Society, 45, 543-549. http://dx.doi.org/10.1111/j.1532-5415.1997.tb03085.x

[70] Trento, M., Passera, P., Tomalino, M., et al. (2001) Group Visits Improve Metabolic Control in Type 2 Diabetes: A 2-Year Follow-Up. Diabetes Care, 24, 995-1000. http://dx.doi.org/10.2337/diacare.24.6.995

\section{Submit or recommend next manuscript to SCIRP and we will provide best service for you:}

Accepting pre-submission inquiries through Email, Facebook, LinkedIn, Twitter, etc.

A wide selection of journals (inclusive of 9 subjects, more than 200 journals)

Providing 24-hour high-quality service

User-friendly online submission system

Fair and swift peer-review system

Efficient typesetting and proofreading procedure

Display of the result of downloads and visits, as well as the number of cited articles

Maximum dissemination of your research work

Submit your manuscript at: http://papersubmission.scirp.org/ 